\title{
A Propensity Score-Matched Cohort Study to Evaluate the Association of Lymph Node Retrieval with Long-Term Overall Survival in Patients with Esophageal Cancer
}

\author{
Leonie R. van der Werf, MD ${ }^{1,2}$ (D), Elske Marra, PhD ${ }^{2}$, Suzanne S. Gisbertz, PhD ${ }^{3}$, Bas P. L. Wijnhoven, PhD ${ }^{1}$, and \\ Mark I. van Berge Henegouwen, $\mathbf{P h D}^{3}$ \\ ${ }^{1}$ Department of Surgery, Erasmus University Medical Center, Rotterdam, The Netherlands; ${ }^{2}$ Scientific Bureau, Dutch \\ Institute for Clinical Auditing, Leiden, The Netherlands; ${ }^{3}$ Department of Surgery, Amsterdam University Medical Centers, \\ University of Amsterdam, Amsterdam, The Netherlands
}

\begin{abstract}
Background. Previous studies evaluating the association of lymph node (LN) yield and survival presented conflicting results and many may be influenced by confounding and stage migration.

Objective. This study aimed to evaluate whether the quality indicator 'retrieval of at least $15 \mathrm{LNs}$ ' is associated with better long-term survival and more accurate pathological staging in patients with esophageal cancer treated with neoadjuvant chemoradiotherapy and resection.

Methods. Data of esophageal cancer patients who underwent neoadjuvant chemoradiotherapy and surgery between 2011 and 2016 were retrieved from the Dutch Upper Gastrointestinal Cancer Audit. Patients with $<15$ and $\geq 15$ LNs were compared after propensity score matching based on patient and tumor characteristics. The primary endpoint was 3-year survival. To evaluate the effect of $\mathrm{LN}$ yield on the accuracy of pathological staging, pathological $\mathrm{N}$ stage was evaluated and 3-year survival was analyzed in a subgroup of patients with node-negative disease.
\end{abstract}

Electronic supplementary material The online version of this article (https://doi.org/10.1245/s10434-020-09142-w) contains supplementary material, which is available to authorized users.

(C) The Author(s) 2020

First Received: 18 February 2020

Accepted: 25 July 2020;

Published Online: 16 October 2020

L. R. van der Werf, MD

e-mail: 1.r.vdwerf@gmail.com
Results. In 2260 of 3281 patients $(67 \%) \geq 15$ LNs were retrieved. In total, 992 patients with $\geq 15$ LNs were matched to 992 patients with $<15$ LNs. The 3-year survival did not differ between the two groups (57\% vs. 54\%; $p=0.28)$. $\mathrm{pN}+$ was scored in $41 \%$ of patients with $\geq 15$ LNs versus $35 \%$ of patients with $<15$ LNs. For nodenegative patients, the 3-year survival was significantly better for patients with $\geq 15 \mathrm{LNs}(69 \%$ vs. $61 \%, p=0.01)$. Conclusions. $n$ this propensity score-matched cohort, 3 -year survival was comparable for patients with $\geq 15$ LNs, although increasing nodal yield was associated with more accurate staging. In node-negative patients, 3-year survival was higher for patients with $\geq 15$ LNs.

Although the extent of lymphadenectomy remains controversial, especially in the era of neoadjuvant therapy, clinical audits often use the number of retrieved lymph nodes (LNs) as a quality indicator for esophageal cancer surgery. In 2013, the percentage of patients with at least 15 retrieved LNs has been introduced as one of the quality indicators in the Dutch Upper Gastrointestinal Cancer Audit (DUCA). ${ }^{1}$ The number of retrieved LNs has increased since the introduction of this quality indicator; ${ }^{2}$ however, it is unclear whether this increase is the result of a more extensive LN dissection or a more extensive pathological examination. Therefore, it might be questioned whether the improvement in LN retrieval since the introduction of this quality indicator in the DUCA has improved locoregional tumor control and thereby might have affected overall survival. 
It has been shown that several patient and disease characteristics are associated with the number of retrieved LNs. $^{2}$ Preoperative weight loss of 0-10 kg, low Charlson comorbidity score, and higher clinical $\mathrm{N}$ stage were shown to be associated with high LN yield (at least 15 retrieved LNs). When evaluating the association of the number of retrieved LNs with long-term survival, these confounding factors may influence results significantly. Another concern regarding the comparison of outcomes of low versus high LN yield is stage migration. ${ }^{3}$ The accuracy of pathological $\mathrm{N}$ stage increases when evaluating more LNs in the pathological examination, and retrieval of more LNs also lowers the risk of leaving positive LNs behind.

The primary aim of this study was to evaluate the association of the quality indicator 'retrieval of at least 15 LNs' with long-term survival in a recent national cohort of patients who underwent an esophagectomy after neoadjuvant chemoradiotherapy, with use of a propensity score matching method to minimize the effect of confounding. The secondary aim of this study was to evaluate the association of the quality indicator 'retrieval of at least 15 LNs' with the accuracy of pathological staging in this propensity score-matched cohort.

\section{METHODS}

\section{Study Design}

For this population-based cohort study, data were retrieved from the DUCA database and a national health care insurance database (Vektis), including date of death. ${ }^{1,4}$ All Dutch inhabitants with health care insurance are included in the Vektis database; since health care insurance is obligatory in The Netherlands, almost all Dutch inhabitants $(99 \%)$ are registered in the Vektis database. ${ }^{5}$ The validity of the merged dataset is estimated at $94 \% .{ }^{6}$ For this study, no ethical approval or informed consent was required under Dutch law. The Scientific Bureau and Scientific Committee of the DUCA approved the study design.

\section{Patient Population}

All patients with primary esophageal or esophagogastric junction cancer who underwent neoadjuvant chemoradiotherapy followed by esophagectomy with curative intent in the period between 2011 and 2016 were included. Patients with a resection other than elective were excluded, as were patients with a non-curative esophagectomy (as defined by the surgeon at the end of the operation). Patients were also excluded if data on sex, date of birth, 30-day survival status, number of retrieved LNs, or clinical $\mathrm{N}$ category were missing in the DUCA dataset.

\section{Propensity Score Matching}

A propensity score matching method was chosen because correction for confounding factors with a Cox proportional hazard model is not allowed since the assumptions that are needed for this model of proportional hazard over time could not be met in our cohort as the number of LNs increased with time. Propensity score matching was used to create two groups of patients with comparable patient characteristics and disease characteristics. The selection of characteristics that were used for matching was based on the literature. Patients with $<15 \mathrm{LNs}$ were matched to patients with $\geq 15 \mathrm{LNs}$, on the following characteristics: age, American Society of Anesthesiologists (ASA) score, Charlson comorbidity score, preoperative weight loss, tumor location, clinical T category, clinical N category, clinical M category, histological subtype, and differentiation grade. Characteristics associated with the depending variable (number of retrieved LNs) were not used for matching because of this association; for example, approach (transthoracic vs. transhiatal $^{7}$ and hospital vol$u_{\mathrm{me}}{ }^{2}$ ). For sensitivity analyses, there were also groups matched for $\geq 10, \geq 20$, and $\geq 30$ LNs.

\section{Outcomes}

The primary endpoint of this study was 3-year survival in patients with $\geq 15$ and $<15$ LNs resected during esophagectomy for esophageal or esophagogastric junction cancer. In the first part of this paper, the 3-year survival was compared between the groups with $\geq 15$ and $<15$ LNs. For sensitivity analyses, the 3-year survival was also compared for the groups with $\geq 10$ versus $<10$, $\geq 20$ versus $<20$, and $\geq 30$ versus $<30$ LNs. The secondary endpoints in this study were pathological $\mathrm{N}$ stage in the groups with $\geq 15$ and $<15$ LNs. To estimate the accuracy of pathological $\mathrm{N}$ staging, in the subgroup of patients with node-negative disease or $\mathrm{pN} 1$ disease, the 3-year survival was compared between the groups with $\geq 15$ and $<15$ LNs. Other $\mathrm{N}$ categories were not chosen for evaluation in a subgroup analysis because of heterogenicity within these groups, which might affect outcomes.

\section{Statistical Analyses}

A propensity score-matched analysis was used to balance observed covariates between the group of patients with $\geq 15$ retrieved LNs and the group of patients with $<15$ retrieved LNs. The groups were matched using the nearest-neighbor method with a caliper of 0.20 . Balances in patient and disease characteristics between the groups were measured using the standardized mean difference; differences of more than $10 \%$ represent inadequate balance. Overall survival of the groups was analyzed using Kaplan- 


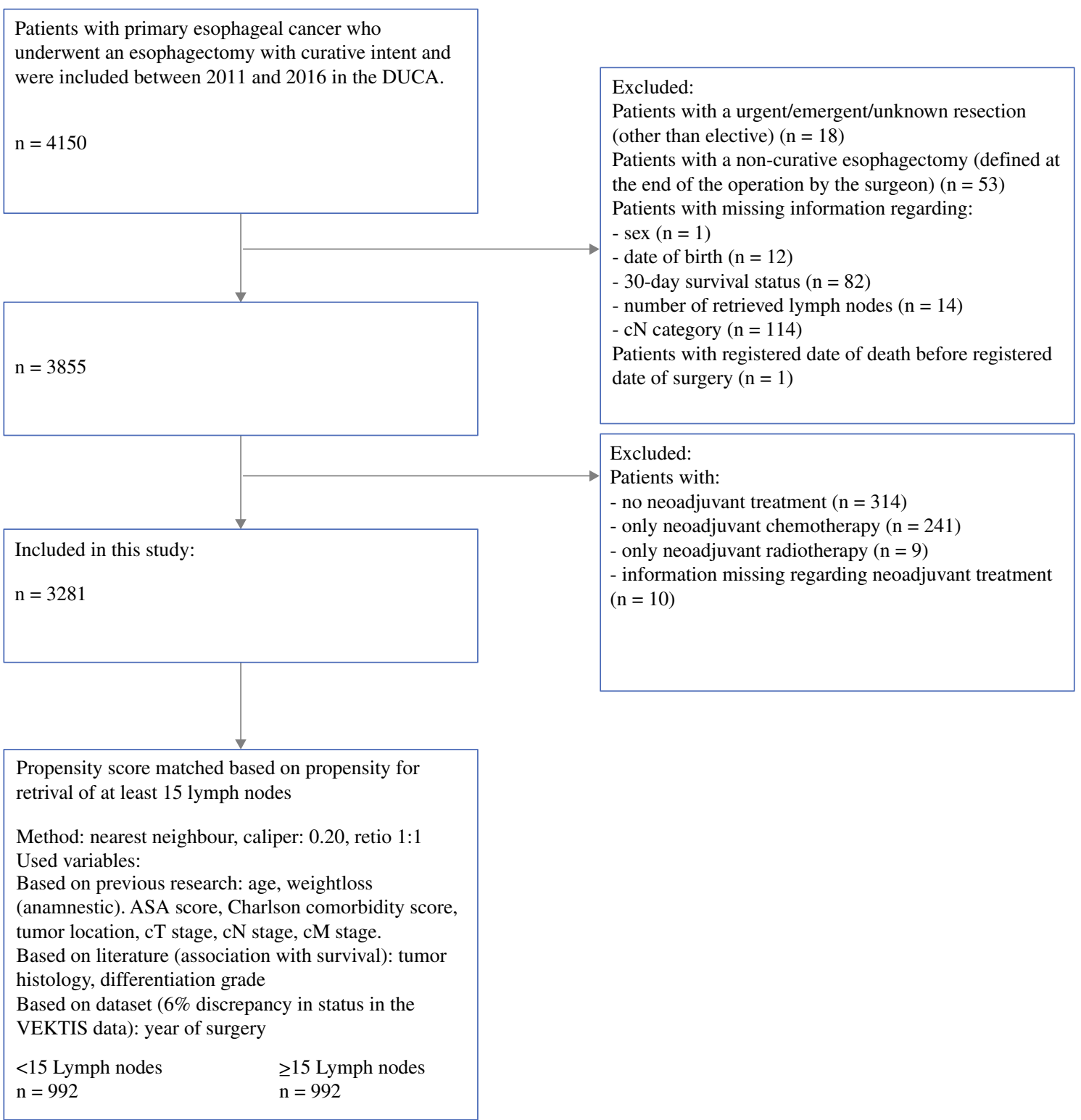

FIG. 1 Inclusion and exclusion criteria and propensity score matching. DUCA Dutch Upper Gastrointestinal Cancer Audit, ASA American Society of Anesthesiologists

Meier survival curves with $95 \%$ confidence intervals (CIs) and 3-year survival rate. These outcomes were compared using log-rank analyses. The pathological $\mathrm{N}$ stages were compared between the two groups using $\chi^{2}$ analyses. Missing items were categorized in a separate group. For sensitivity analyses, comparisons were also made for groups with $\geq 10$ versus $<10, \geq 20$ versus $<20$, and $\geq 30$ versus $<30$ LNs. For all analyses, statistical significance was defined as $p<0.05$. All analyses were performed using SPSS version 24 (IBM Corporation, Armonk, NY, USA) and R studio version 1.1.456 (RStudio, Inc, packages: 'MatchIt' and 'optmatch').

\section{RESULTS}

\section{Study Population}

A total of 3281 esophageal cancer patients underwent neoadjuvant chemoradiotherapy followed by curative esophagectomy between 2011 and 2016 and were eligible for this study according to the inclusion and exclusion criteria (Fig. 1). Retrieval of at least 15 LNs was achieved in 2260 (67\%) patients.

With propensity score matching, 992 patients with $<15$ retrieved LNs were matched to 992 patients with $\geq 15$ retrieved LNs. Patient, disease, and treatment characteristics are shown in Table 1. 
TABLE 1 Basic characteristics of the total cohort and the propensity score-matched cohort

\begin{tabular}{|c|c|c|c|c|c|c|}
\hline \multirow[t]{2}{*}{ Total cohort } & \multicolumn{6}{|c|}{ Propensity score-matched cohort } \\
\hline & $\begin{array}{l}<15 \text { lymph } \\
\text { nodes }\end{array}$ & $\begin{array}{l}\geq 15 \text { lymph } \\
\text { nodes }\end{array}$ & SMD & $\begin{array}{l}<15 \text { lymph } \\
\text { nodes }\end{array}$ & $\begin{array}{l}\geq 15 \text { lymph } \\
\text { nodes }\end{array}$ & SMD \\
\hline Total & 1021 & 2260 & & 992 & 992 & \\
\hline \multicolumn{7}{|l|}{ Sex } \\
\hline Male & $809(79.2)$ & $1756(77.7)$ & 0.037 & $783(78.9)$ & $776(78.2)$ & 0.017 \\
\hline Female & $212(20.8)$ & $504(22.3)$ & & $209(21.1)$ & $216(21.8)$ & \\
\hline Age, years [mean $(\mathrm{SD})]$ & $65.50(8.62)$ & $64.25(8.77)$ & 0.144 & $65.28(8.57)$ & $65.30(8.63)$ & 0.002 \\
\hline \multicolumn{7}{|l|}{ ASA score } \\
\hline I & $156(15.3)$ & $422(18.7)$ & 0.124 & $155(15.6)$ & $154(15.5)$ & 0.052 \\
\hline II & $622(60.9)$ & $1372(60.7)$ & & $607(61.2)$ & $601(60.6)$ & \\
\hline III & $231(22.6)$ & $453(20.0)$ & & $220(22.2)$ & $230(23.2)$ & \\
\hline IV & $3(0.3)$ & $6(0.3)$ & & $3(0.3)$ & $1(0.1)$ & \\
\hline Unknown & $9(0.9)$ & $7(0.3)$ & & $7(0.7)$ & $6(0.6)$ & \\
\hline \multicolumn{7}{|l|}{ Charlson comorbidity score } \\
\hline 0 & $483(47.3)$ & $1153(51.0)$ & 0.091 & $473(47.7)$ & $471(47.5)$ & 0.064 \\
\hline 1 & $258(25.3)$ & $572(25.3)$ & & $251(25.3)$ & $275(27.7)$ & \\
\hline $2+$ & $280(27.4)$ & $535(23.7)$ & & $268(27.0)$ & $246(24.8)$ & \\
\hline \multicolumn{7}{|l|}{ Body mass index } \\
\hline$<20$ & $69(6.8)$ & $145(6.4)$ & 0.07 & $68(6.9)$ & $60(6.0)$ & 0.056 \\
\hline $20-24$ & $380(37.2)$ & $862(38.1)$ & & $366(36.9)$ & $374(37.7)$ & \\
\hline $25-29$ & $387(37.9)$ & $890(39.4)$ & & $377(38.0)$ & $392(39.5)$ & \\
\hline $29+$ & $170(16.7)$ & $342(15.1)$ & & $166(16.7)$ & $153(15.4)$ & \\
\hline Unknown & $15(1.5)$ & $21(0.9)$ & & $15(1.5)$ & $13(1.3)$ & \\
\hline \multicolumn{7}{|l|}{ Weight loss (anamnestic) } \\
\hline$<10 \mathrm{~kg}$ & 731 (71.6) & $1763(78.0)$ & 0.195 & $714(72.0)$ & $723(72.9)$ & 0.045 \\
\hline $10.1-15 \mathrm{~kg}$ & $77(7.5)$ & $139(6.2)$ & & $74(7.5)$ & $65(6.6)$ & \\
\hline$>15 \mathrm{~kg}$ & $40(3.9)$ & $113(5.0)$ & & $39(3.9)$ & $44(4.4)$ & \\
\hline Unknown & $173(16.9)$ & $245(10.8)$ & & $165(16.6)$ & $160(16.1)$ & \\
\hline \multicolumn{7}{|l|}{ Tumor location } \\
\hline Proximal/mid thoracic & $105(10.3)$ & $357(15.8)$ & 0.209 & $105(10.6)$ & $111(11.2)$ & 0.053 \\
\hline Distal & $663(64.9)$ & $1490(65.9)$ & & $654(65.9)$ & $629(63.4)$ & \\
\hline Gastroesophageal junction & $253(24.8)$ & $413(18.3)$ & & $233(23.5)$ & $252(25.4)$ & \\
\hline \multicolumn{7}{|l|}{ cT category } \\
\hline cT0-1 & $17(1.7)$ & $26(1.2)$ & 0.073 & $16(1.6)$ & $10(1.0)$ & 0.059 \\
\hline $\mathrm{cT} 2$ & $212(20.8)$ & $425(18.8)$ & & $202(20.4)$ & $197(19.9)$ & \\
\hline cT3 & $736(72.1)$ & $1679(74.3)$ & & $720(72.6)$ & $727(73.3)$ & \\
\hline cT4 & $35(3.4)$ & $74(3.3)$ & & $33(3.3)$ & $37(3.7)$ & \\
\hline cTx/Unknown & $21(2.1)$ & $56(2.5)$ & & $21(2.1)$ & $21(2.1)$ & \\
\hline \multicolumn{7}{|l|}{$\mathrm{cN}$ category } \\
\hline $\mathrm{cNO}$ & $365(35.7)$ & $724(32.0)$ & 0.104 & $350(35.3)$ & $352(35.5)$ & 0.048 \\
\hline $\mathrm{cN} 1$ & $446(43.7)$ & $987(43.7)$ & & $435(43.9)$ & $448(45.2)$ & \\
\hline $\mathrm{cN} 2$ & $177(17.3)$ & $464(20.5)$ & & $174(17.5)$ & $164(16.5)$ & \\
\hline $\mathrm{cN} 3$ & $22(2.2)$ & $61(2.7)$ & & $22(2.2)$ & $17(1.7)$ & \\
\hline $\mathrm{cN} 4$ & $11(1.1)$ & $24(1.1)$ & & $11(1.1)$ & $11(1.1)$ & \\
\hline \multicolumn{7}{|l|}{$\mathrm{cM}$ category } \\
\hline $\mathrm{cM} 0$ & $990(97.0)$ & $2208(97.7)$ & 0.051 & $961(96.9)$ & $968(97.6)$ & 0.048 \\
\hline $\mathrm{cM}+$ & $6(0.6)$ & $13(0.6)$ & & $6(0.6)$ & $6(0.6)$ & \\
\hline cMx/Unknown & $25(2.4)$ & $39(1.7)$ & & $25(2.5)$ & $18(1.8)$ & \\
\hline
\end{tabular}


TABLE 1 (continued)

\begin{tabular}{|c|c|c|c|c|c|c|}
\hline \multirow[t]{2}{*}{ Total cohort } & \multicolumn{6}{|c|}{ Propensity score-matched cohort } \\
\hline & $\begin{array}{l}<15 \text { lymph } \\
\text { nodes }\end{array}$ & $\begin{array}{l}\geq 15 \text { lymph } \\
\text { nodes }\end{array}$ & SMD & $\begin{array}{l}<15 \text { lymph } \\
\text { nodes }\end{array}$ & $\begin{array}{l}\geq 15 \text { lymph } \\
\text { nodes }\end{array}$ & SMD \\
\hline \multicolumn{7}{|l|}{ Histological type } \\
\hline Adenocarcinoma & $728(71.3)$ & $1554(68.8)$ & \multirow[t]{5}{*}{0.073} & 705 (71.1) & $721(72.7)$ & \multirow[t]{5}{*}{0.075} \\
\hline Squamous cell carcinoma & $164(16.1)$ & $423(18.7)$ & & $162(16.3)$ & $149(15.0)$ & \\
\hline Other & $19(1.9)$ & $43(1.9)$ & & $18(1.8)$ & $15(1.5)$ & \\
\hline Not applicable & $81(7.9)$ & $183(8.1)$ & & $80(8.1)$ & $88(8.9)$ & \\
\hline Unknown & $29(2.8)$ & $57(2.5)$ & & $27(2.7)$ & $19(1.9)$ & \\
\hline \multicolumn{7}{|l|}{ Differentiation grade } \\
\hline Well/moderate & $358(35.1)$ & $868(38.4)$ & \multirow[t]{4}{*}{0.092} & $348(35.1)$ & $350(35.3)$ & \multirow[t]{4}{*}{0.059} \\
\hline Poor & $276(27.0)$ & $600(26.5)$ & & $269(27.1)$ & 277 (27.9) & \\
\hline Not judgeable & $184(18.0)$ & $340(15.0)$ & & $176(17.7)$ & $155(15.6)$ & \\
\hline Unknown & $203(19.9)$ & $452(20.0)$ & & $199(20.1)$ & $210(21.2)$ & \\
\hline \multicolumn{7}{|l|}{ Year of surgery } \\
\hline 2011 & $202(19.8)$ & $189(8.4)$ & \multirow[t]{6}{*}{0.482} & $179(18.0)$ & $146(14.7)$ & \multirow[t]{6}{*}{0.145} \\
\hline 2012 & $187(18.3)$ & $287(12.7)$ & & $181(18.2)$ & $193(19.5)$ & \\
\hline 2013 & $188(18.4)$ & $322(14.2)$ & & $188(19.0)$ & $169(17.0)$ & \\
\hline 2014 & $150(14.7)$ & $429(19.0)$ & & $150(15.1)$ & $190(19.2)$ & \\
\hline 2015 & $167(16.4)$ & $504(22.3)$ & & $167(16.8)$ & $155(15.6)$ & \\
\hline 2016 & $127(12.4)$ & $529(23.4)$ & & $127(12.8)$ & $139(14.0)$ & \\
\hline \multicolumn{7}{|l|}{ Resection margins (pathological) } \\
\hline $\mathrm{pR} 0$ & $962(94.2)$ & $2152(95.2)$ & \multirow[t]{3}{*}{0.047} & $935(94.3)$ & $944(95.2)$ & \multirow[t]{3}{*}{0.05} \\
\hline $\mathrm{pR}+$ & $47(4.6)$ & 89 (3.9) & & $46(4.6)$ & $41(4.1)$ & \\
\hline Unknown & $12(1.2)$ & $19(0.8)$ & & $11(1.1)$ & $7(0.7)$ & \\
\hline \multicolumn{7}{|c|}{ Other characteristics (matching not based on these variables) } \\
\hline \multicolumn{7}{|l|}{ Procedure } \\
\hline TTE (thoracic open) & $149(14.6)$ & $402(17.8)$ & \multirow[t]{5}{*}{0.843} & $148(14.9)$ & $167(16.8)$ & \multirow[t]{5}{*}{0.7} \\
\hline TTE (thoracic MI) & $308(30.2)$ & $1426(63.1)$ & & $307(30.9)$ & $592(59.7)$ & \\
\hline THE (open) & $441(43.2)$ & $296(13.1)$ & & $417(42.0)$ & $163(16.4)$ & \\
\hline THE (MI) & $116(11.4)$ & $133(5.9)$ & & $113(11.4)$ & $68(6.9)$ & \\
\hline Unknown & $7(0.7)$ & $3(0.1)$ & & $7(0.7)$ & $2(0.2)$ & \\
\hline \multicolumn{7}{|l|}{ Annual hospital volume } \\
\hline $0-25$ & $226(22.1)$ & $187(8.3)$ & \multirow[t]{4}{*}{0.446} & $223(22.5)$ & $86(8.7)$ & \multirow[t]{4}{*}{0.426} \\
\hline $26-50$ & $527(51.6)$ & $1304(57.7)$ & & $511(51.5)$ & $578(58.3)$ & \\
\hline $50+$ & $250(24.5)$ & $765(33.8)$ & & $240(24.2)$ & $324(32.7)$ & \\
\hline Stopped with esophageal surgery before 2014 & $18(1.8)$ & $4(0.2)$ & & $18(1.8)$ & $4(0.4)$ & \\
\hline
\end{tabular}

Data are expressed as $n(\%)$ unless otherwise specified

SMD standard mean difference, $S D$ standard deviation, ASA American Society of Anesthesiologists, TTE trans-thoracic esophagectomy, THE transhiatal esophagectomy, $M I$ myocardial infarction

Overall Survival Outcomes between Patients with $\geq 15$ versus $<15$ Retrieved Lymph Nodes

The overall survival curves in the propensity scorematched cohort are presented in Fig. 2. The 3-year survival was not significantly different between the group of patients with $\geq 15$ retrieved LNs and patients with $<15$ retrieved LNs (57\% vs. 54\%; $p=0.28)$. In sensitivity analyses, there were also no differences in 3-year survival when comparing patients with $\geq 10$ LNs versus patients with $<10$ LNs $(52 \%$ vs. $54 \% ; p=0.31)$, patients with $\geq 20 \mathrm{LNs}$ versus patients with $<20 \mathrm{LNs}(55 \%$ vs. $55 \%$; $p=0.88$ ), and patients with $\geq 30$ LNs versus patients 
FIG. 2 Overall survival curves with $95 \%$ confidence interval of the subgroups with $\geq 15 \mathrm{LNs}$ versus $<15 \mathrm{LNs}$ in the propensity matched cohort. $L N s$ lymph nodes
Overall survival of patients with esophageal cancer who underwent curative surgery between 2011-2016 By number of lymph nodes

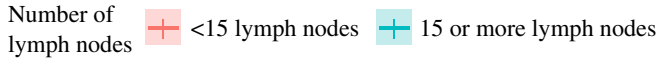

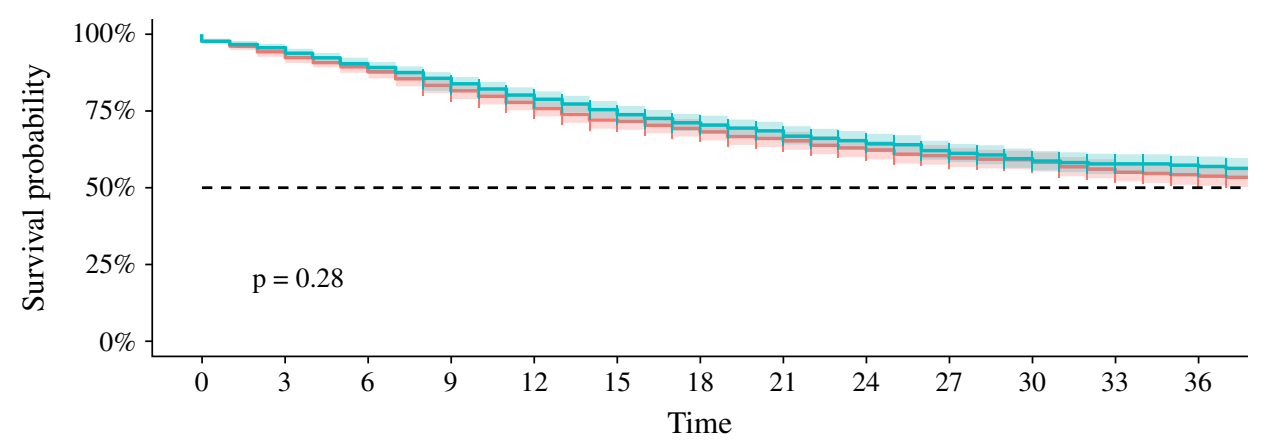

\begin{tabular}{|c|c|c|c|c|c|c|c|c|c|c|c|c|c|}
\hline$\approx$ & Numb & $r$ at $r$ & & & & & & & & & & & \\
\hline- & 992 & 933 & 886 & 817 & 741 & 668 & 623 & 573 & 514 & 473 & 441 & 400 & 363 \\
\hline$=$ & 992 & 947 & 897 & 836 & 755 & 680 & 619 & 574 & 522 & 469 & 424 & 399 & 372 \\
\hline$\Sigma$ & 0 & 3 & 6 & 9 & 12 & 15 & 18 & 21 & 24 & 27 & 30 & 33 & 36 \\
\hline
\end{tabular}

TABLE 2 Pathological staging of the subgroups with $\geq 15$ versus $<15 \mathrm{LNs}$ in the propensity matched cohort

\begin{tabular}{cccc}
\hline Total & $<15$ lymph nodes & $\begin{array}{l}\geq 15 \text { lymph nodes } \\
992\end{array}$ & $p$ Value \\
& 992 & & \\
\hline pT stage & & $374(37.7)$ & 0.393 \\
pT0-1 & $393(39.6)$ & $206(20.8)$ & \\
pT2 & $223(22.5)$ & $366(36.9)$ & \\
pT3 & $332(33.5)$ & $5(0.5)$ & $<0.001$ \\
pT4 & $2(0.2)$ & $41(4.1)$ & \\
pTx & $42(4.2)$ & & \\
pN stage & & $583(58.8)$ & \\
pN0 & $647(65.2)$ & $208(21.0)$ & \\
pN1 & $202(20.4)$ & $108(10.9)$ & \\
pN2 & $90(9.1)$ & $36(5.7)$ & \\
pN3 & $15(1.5)$ & & \\
pNx & $38(3.8)$ & & \\
\hline
\end{tabular}

Data are expressed as $n(\%)$

with $<30$ LNs $(59 \%$ vs. $59 \%$; $p=0.54)$ [electronic supplementary Figs. 1, 2, and 3].

\section{Pathological Staging}

In the propensity score-matched cohort, the clinical $\mathrm{T}$ and $\mathrm{N}$ stages were well-balanced between the groups with $\geq 15$ and $<15$ retrieved LNs. After pathological staging, patients with $\geq 15$ retrieved LNs were staged with higher $\mathrm{N}$ stages $(p<0.001)$ [Table 2].
The 3-year survival in the subgroup of patients with pathological N0 status was significantly higher for patients with $\geq 15$ retrieved LNs compared with patients with $<$ 15 LNs $(69 \%$ vs. $61 \%, p=0.01)$ [Fig. 3]. For the subgroup of patients with pathological N1 status, 3-year survival was not significantly different between the groups with $\geq 15$ and $<15$ LNs $(49 \%$ vs. $43 \% ; p=0.15)$ [Fig. 4].

\section{DISCUSSION}

This study investigated whether the quality indicator 'retrieval of at least 15 LNs' was associated with better long-term survival and more accurate pathological staging in patients with esophageal cancer treated with neoadjuvant chemoradiotherapy and resection. The results of this study showed that there was no difference in 3-year survival between patients with retrieval of at least 15 LNs versus patients with retrieval of $<15$ LNs. In addition, retrieval of at least 10, 20, or $30 \mathrm{LNs}$ was not associated with better 3-year survival compared with patients with fewer LNs ( $<10,<20$, and $<30$, respectively); however, retrieval of at least 15 LNs was associated with more accurate pathological staging. Positive LNs were found more often in patients with at least 15 retrieved LNs, leading to higher pathological $\mathrm{N}$ stages. Furthermore, the 3-year survival in the subgroup of patients with pathological node-negative disease was significantly higher for patients with at least 15 LNs compared with patients with $<15$ LNs. These findings support the idea of stage migration; patients with low LN retrieval are likely understaged because positive LNs 
FIG. 3 Overall survival curves with $95 \%$ confidence interval of the subgroups with $<15 \mathrm{LNs}$ versus $\geq 15 \mathrm{LNs}$ in the propensity matched cohort with pN0 stage disease. LNs lymph nodes

FIG. 4 Overall survival curves with $95 \%$ confidence interval of the subgroups with $\geq 15 \mathrm{LNs}$ versus $<15$ LNs in the propensity matched cohort with pN1 stage disease. LNs lymph nodes
Overall survival of patients with esophageal cancer who underwent curative surgery between 2011-2016 and had a pNO stage

By number of lymph nodes

$$
<15 \text { lymph nodes }+15 \text { or more lymph nodes }
$$

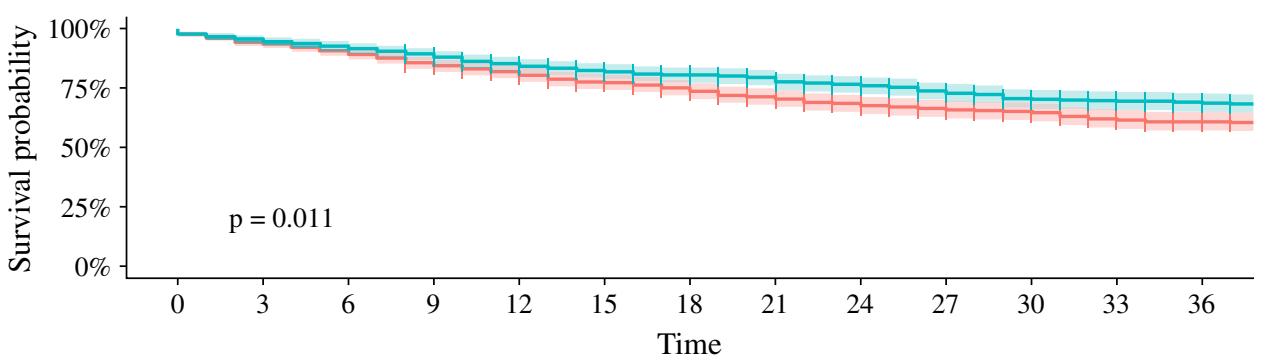

Number at risk

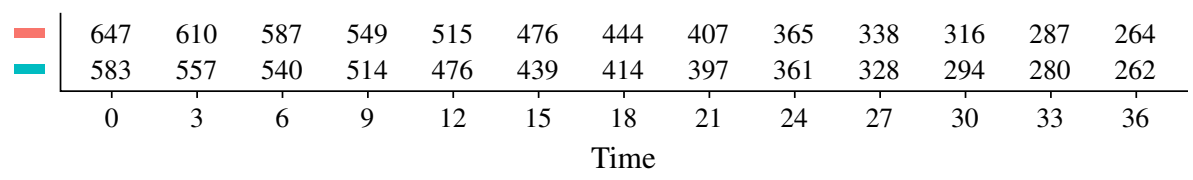

Overall survival of patients with esophageal cancer who underwent curative surgery between 2011-2016 and had a pN1 stage

By number of lymph nodes

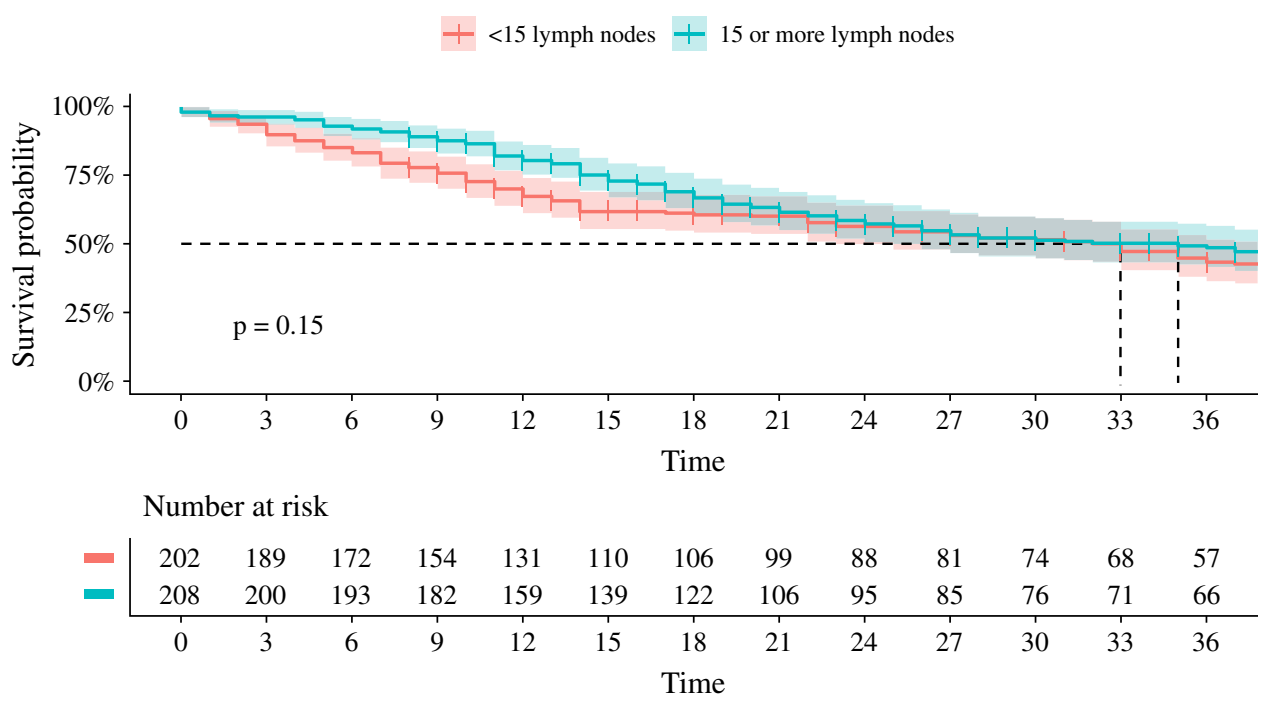

have been left behind in the resection specimen or may have been left behind in the patient. This may explain the lower 3-year survival for patients with pathological nodenegative disease with $<15$ LNs compared with patients with at least 15 retrieved LNs.

The therapeutic value of a higher number of retrieved LNs after neoadjuvant therapy is a controversial issue in cancer surgery. For esophageal cancer, many papers have been published on this topic and most studies show an association between the number of nodes retrieved and survival. ${ }^{8,9}$ The findings of the current study show this relationship only for patients with pathological node-negative disease; in the total group, no relation between LN retrieval and survival was seen. A possible explanation may be patient selection; the patient cohort that is selected covers a more recent period than most other studies. Dutch institutions have started various improvement processes in recent years. The number of LNs resected was implemented as a quality indicator in 2013 , which has resulted in an increase in the number of retrieved LNs reported ${ }^{10}$ The 
increase in reported LN yield may not only be an effect of more extended LN dissections but may also be due to more detailed pathological examination; therefore, the extra number of examined and counted LNs does not automatically imply an extended lymphadenectomy.

The outcome that there was no survival difference between the two groups may also be due to recent improvements in preoperative and intraoperative imaging, which may lead to better-targeted lymphadenectomy. Better-targeted lymphadenectomy might ensure the quality of $\mathrm{LN}$ dissection, but is not necessarily reflected in the high number of LNs. In The Netherlands, the use of preoperative positron emission tomography/computed tomography (PET/CT) and endoscopic ultrasound (EUS) for clinical staging increased. In 2017, a PET/CT was performed in $93 \%$ of patients, an EUS was performed in $67 \%$ of patients, and an EUS with biopsy was performed in $18 \%$ of patients. ${ }^{11}$ For patients with esophageal squamous cell carcinoma, a recent meta-analysis showed that the pooled sensitivity of PET/CT for detection of regional LN metastasis was $66 \%(95 \%$ CI $66-78 \%) .{ }^{12}$ Another recent meta-analysis evaluated the sensitivity of PET/CT and EUS for detecting residual disease after neoadjuvant chemoradiotherapy at the primary tumor site or regional LNs. ${ }^{13}$ For PET/CT, the sensitivity rates for detection of residual disease in LNs ranged between 0 and $65 \%$. Due to the low number of studies evaluating the sensitivity of $\mathrm{PET} / \mathrm{CT}$ for detection of residual disease in LNs, the authors could not determine the pooled sensitivity for PET/ CT. For EUS, the pooled sensitivity for detection of residual disease in LNs was $68 \%$ (95\% CI 54-80\%).

In future, intraoperative imaging as fluorescence imaging may also help to identify affected LNs. ${ }^{14}$

A limitation of this study was that with propensity score matching, it was possible to only compare two groups and it was not possible to use the number of LNs as a continuous outcome. Therefore, identifying an optimal number of LNs was not possible. Additionally, not analyzing the number of LNs as a continuous outcome could have been the reason that no survival difference was seen between patients with a low versus high number of retrieved LNs. Another limitation is that this study did not include which LN stations were dissected, therefore it is not known whether these $\mathrm{LN}$ stations influenced survival.

A further study with more focus on the extent of LN dissection is needed. It would be desirable to identify an optimal number of LNs that should be removed, or to identify which LN stations should be dissected. For this purpose, the TIGER study is under way $;^{15}$ the aim of this international observational cohort study is to evaluate the distribution of LN metastases in esophageal carcinoma. In 50 centers, specimens of patients following transthoracic esophagectomy with a two- or three-field lymphadenectomy will be evaluated by a pathologist. The distribution of LN metastases will be evaluated in relation to tumor histology, tumor location, invasion depth, number of LNs and LN metastases, preoperative diagnostics, neoadjuvant therapy, and (disease-free) survival.

Taken together, although the findings of the current study did not show that retrieval of at least 15 LNs was associated with improved 3-year survival, it did show that it was associated with more accurate pathological staging. Since accurate staging is important to determine prognosis, and therefore contributes to better quality of care, it can be concluded that 'retrieval of at least 15 LNs' is a relevant quality indicator.

DISCLOSURES Leonie R. van der Werf, Elske Marra, Suzanne S. Gisbertz, Bas P.L. Wijnhoven, and Mark I. van Berge Henegouwen declare no conflicts of interest.

OPEN ACCESS This article is licensed under a Creative Commons Attribution 4.0 International License, which permits use, sharing, adaptation, distribution and reproduction in any medium or format, as long as you give appropriate credit to the original author(s) and the source, provide a link to the Creative Commons licence, and indicate if changes were made. The images or other third party material in this article are included in the article's Creative Commons licence, unless indicated otherwise in a credit line to the material. If material is not included in the article's Creative Commons licence and your intended use is not permitted by statutory regulation or exceeds the permitted use, you will need to obtain permission directly from the copyright holder. To view a copy of this licence, visit http://creativecommons. org/licenses/by/4.0/.

\section{REFERENCES}

1. Busweiler LA, Wijnhoven BP, van Berge Henegouwen MI, et al. Early outcomes from the Dutch Upper Gastrointestinal Cancer Audit. Br J Surg 2016; 103: 1855-1863.

2. van der Werf LR, Dikken JL, van Berge Henegouwen MI, et al. A Population-based Study on Lymph Node Retrieval in Patients with Esophageal Cancer: Results from the Dutch Upper Gastrointestinal Cancer Audit. Ann Surg Oncol 2018; 25: 1211-1220.

3. Herrera LJ. Extent of Lymphadenectomy in Esophageal Cancer: How Many Lymph Nodes Is Enough? Ann Surg Oncol 2010; 17: 676-678.

4. Vektis. 2018. Available at: https://www.vektis.nl/over-vektis.

5. statistiek Cbv. Onverzekerden tegen ziektekosten; GGD regio 2006-2010. 2012. Available at: https://opendata.cbs.nl/statline/\#/ CBS/nl/dataset/71431ned/table?ts=1533116782288.

6. van der Werf LR, Wijnhoven BP, Fransen LFC, et al. A national cohort study evaluating the association between short-term outcomes and long-term survival after esophageal and gastric cancer surgery Annals of Surgery 2019;270(5):868-876.

7. Hulscher JB, van Sandick JW, de Boer AG et al. Extended transthoracic resection compared with limited transhiatal resection for adenocarcinoma of the esophagus. N Engl J Med 2002; 347: 1662-1669.

8. Visser E, Markar SR, Ruurda JP et al. Prognostic Value of Lymph Node Yield on Overall Survival in Esophageal Cancer 
Patients: A Systematic Review and Meta-analysis. Ann Surg 2019; 269: 261-268.

9. Ho HJ, Chen HS, Hung WH et al. Survival Impact of Total Resected Lymph Nodes in Esophageal Cancer Patients With and Without Neoadjuvant Chemoradiation. Ann Surg Oncol 2018; 25 : 3820-3832.

10. van der Werf LR, Dikken JL, van Berge Henegouwen MI et al. A Population-based Study on Lymph Node Retrieval in Patients with Esophageal Cancer: Results from the Dutch Upper Gastrointestinal Cancer Audit. Ann Surg Oncol 2018;25(5):1211-1220.

11. Dutch Institute for Clinical Auditing. Annual report: Dutch Upper gastrointestinal Cancer Audit. Dutch Institute for Clinical Auditing; 2017. Available at: https://dica.nl/jaarrapportage-2017 /duca.

12. Jiang C, Chen Y, Zhu Y, Xu Y. Systematic review and metaanalysis of the accuracy of 18F-FDG PET/CT for detection of regional lymph node metastasis in esophageal squamous cell carcinoma. J Thorac Dis 2018; 10: 6066-6076.
13. Eyck BM, Onstenk BD, Noordman BJ, Nieboer D, Spaander $\mathrm{MCW}$, Valkema R, et al. Accuracy of detecting residual disease after neoadjuvant chemoradiotherapy for esophageal cancer: a systematic review and meta-analysis. Ann Surg 2020;271(2):245-256.

14. Yuasa Y, Seike J, Yoshida T et al. Sentinel lymph node biopsy using intraoperative indocyanine green fluorescence imaging navigated with preoperative CT lymphography for superficial esophageal cancer. Ann Surg Oncol 2012; 19: 486-493.

15. Hagens ERC, van Berge Henegouwen MI, van Sandick JW, Cuesta MA, van der Peet DL, Heisterkamp J, et al. Distribution of lymph node metastases in esophageal carcinoma [TIGER study]: study protocol of a multinational observational study. BMC Cancer. 2019;19(1):662.

Publisher's Note Springer Nature remains neutral with regard to jurisdictional claims in published maps and institutional affiliations. 